\title{
Modeling the Cost of Technology Transfer and Economic Growth in Nigeria
}

\author{
Onochie Jude Dieli \\ Prairie View A\&M University \\ Mika Kato \\ Howard University \\ G. Solomon Osho \\ Prairie View A\&M University \\ Stiff Cleveland \\ Prairie View A\&M University
}

Received: November 21, 2019

Accepted: December 12, 2019

Published: December 16, 2019

doi:10.5296/ijrd.v6i2.15872

URL: http://dx.doi.org/10.5296/ijrd.v6i2.15872

\begin{abstract}
This research studies the effects of wireless mobile phone technology on technology transfer and economic growth, and its distributional consequence in Nigeria. After deregulation of telecom industry, wireless technology has become widely available in Nigeria The current study argues that the availability of wireless technology helps to reduce the cost of learning and implementing world technology frontier and thus that it promotes smoother transfer of technology from technologically-advanced countries to Nigeria and brings significant growth in the economy. Using a multi-sector Schumpeterian growth model, thus, it explains the relationship between the cost of technology transfer and economic growth. The model generates two equilibria where the low equilibrium has zero growth. This study shows that a group with low cost of technology transfer is likely to achieve the high growth equilibrium while a group with high cost of technology transfer is likely to achieve the low growth equilibrium. Using the industry-level and the state-level data, the study found that the availability of wireless technology increased transfer of technology measured by the volume of imports and spurred growth in Nigeria. Moreover, the research found that the
\end{abstract}


benefit of the wireless technology is greater for lower income groups and thus the technology helped to reduce distributional inequality of economic benefit.

Keywords: Technology transfer, economic growth, wireless mobile phone technology, monopoly, and deregulation

\section{Introduction}

It is believed that public ownership of enterprises in the developing countries like Nigeria hold down the growth and development of the economic sectors including the telecom sector for decades (Okonjo-Iweala, 2012). This is attributed to the attendant corruption in the management of public enterprises; lack of dedication and patriotism on the side of the workers, untrained manpower/labor and use of obsolete technology in various sectors of the economy. This economic malfunction is also attributed to the inefficient structure of the economy encouraged by the type of political system in practice. In Nigeria previously, most of the sectors were either natural or legal monopolies. However, the restoration of democratic institutions and subsequent implementation of a deregulation policy in 1999 transformed the status of most public enterprises.

The enterprises have become privatized, or, at its verge with the liberalization and deregulation policy implemented by Nigerian government. This leads to the removal of barriers and restrictions to entry into various industries previously owned by the state. The telecommunications sector is one of those sectors privatized which was hitherto controlled by Nigeria Telecommunications (NITEL) - a state owned corporation. It was then a natural monopoly and the cost of entry was enormous. However, the emergence of wireless mobile phone technology made its deregulation possible by reducing the total cost of supplying telecommunications services and products. This opened up the industry for competition. In this study, the current research study would aim to show how this new mobile phone technology has also reduced the cost of transfer of technology to Nigeria from the world technology frontier and subsequently enhanced economic growth. Therefore, the main objective of this study is to analyze how the introduction of wireless mobile phone technology reduced the cost of transfer of technologies from the world technology frontier, and how it has generated economic growth. Thus, this research will attempt to examine whether the availability of telecom technology in Nigeria help to increase transfer of world technology frontier by reducing the cost of transfer? Second, whether the availability of telecom technology help to spur growth in Nigeria?

\section{Previous Studies}

According to Simon Kuznets (1966), modern economic growth implies increase in the stock of useful knowledge and spread of its application. This implies that economic growth of any nation is inseparably connected to international technology transfer. Several research studies have suggested that the technology transfer that takes place among nations and within regions have many mechanisms and channels for its occurrence. These mechanisms often exist independent of other channels. However, the nature and extent of technology transfers and mechanisms are usually influenced by internal government economic/political policies and economic alliances. 


\section{Macrothink}

\subsection{Theoretical Model of Technology Transfer and Growth}

A multi-sector Schumpeterian growth model developed by Aghion and Howitt (2009). The model explains why some countries fail to invest resources to master and adopt new technology and stagnate as a result; while others benefit from technology transfer and continue to advance.

\subsection{Basic Environment}

There is a sequence of discrete time periods. In each period, there are a fixed number of individuals, L. Each individual supplies one unit of labor inelastically. For simplicity, this current research normalizes it to unity. Only one kind of final good is produced using labor and intermediate products in a perfectly competitive market. There is a continuum of intermediate product indexed on the interval $[0,1]$.

A final good is produced by the following Cobb-Douglas technology:

$$
Y_{t}=\int_{0}^{1} A_{t t}^{1-\alpha} x_{t i}^{\alpha} d t
$$

where $x_{i t}$ is the input of intermediate good $\mathrm{i}$ and $A_{i t}$ is the productivity parameter that reflects the latest technology adopted in the intermediate goods sector i. The final good can be consumed or used as an input to the production of intermediate goods or as a resource to implement a new technology. Notice that the final product produced from each intermediate good $i$ is

$$
Y_{i}^{*}-A_{t=}^{1-\kappa} x_{t i}^{\alpha}
$$

In each period, there is only one active firm (i.e., a monopolist) in each intermediate-good sector. Each intermediate good, $x_{i t}$, is produced using the final good as input. Assuming that one unit of final good is required as input to produce one unit of intermediate good.

Then the intermediate-good sector i's profit is

$$
\Pi_{i t}=p_{i t} x_{i t}-x_{i t}
$$

where $\Pi_{t t}$ is the profit in units of final good and $p_{\mathrm{it}}$ is the price of intermediate good i relative to the final good. Recall that the final good market is perfectly competitive and that the equilibrium price of a factor used in a competitive market must be equal to the value of its marginal product. Therefore, from equation (2), the price of each intermediate good is

$$
p_{i t}=\frac{9 F_{i t}}{2 x_{i t}}=\alpha A_{t t}^{1-\alpha} x_{t i}^{\alpha-1}
$$

Then, from equations (3) and (4), each monopolist's problem can be written as 


$$
\max _{\alpha_{i t}} \Pi_{i t}=\alpha A_{i t}^{1-\alpha} x_{i t}^{\alpha}-x_{i t}
$$

From the first-order condition, the equilibrium production of intermediate good i was obtained as:

$$
x_{i t}=\frac{a}{\alpha-\alpha} A_{i t} .
$$

Substituting equation (1.6) into equation (1.4), the equilibrium monopoly price of intermediate-good sector $i$ was obtained as

$$
p_{i t}=\alpha A_{*}{ }^{1-\alpha}\left(\alpha \frac{\Omega}{\alpha-\alpha} A_{t i t}\right)^{\alpha-1}=\frac{1}{\alpha}
$$

Substituting equations (6) and (7) into equation (3), the equilibrium monopoly profit of intermediate-good sector $i$ was obtained as

$$
\Pi_{i t}=(1-\alpha)^{\frac{1+\alpha}{1-\alpha}} \quad A_{i t}=\pi A_{i \omega}
$$

Where

$$
\pi \equiv(1-\alpha) \alpha^{\frac{1+\alpha}{1-\alpha}}
$$

With the equilibrium production of intermediate goods, equation (6), the equilibrium gross output of the final good, equation (1), is

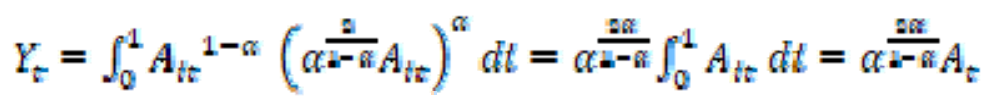

Where

$$
A_{t}=\int_{0}^{1} A_{i t} d i
$$

is the country's average technology level across all intermediate-good sectors?

\subsection{Technology Transfer}

In each period, one entrepreneur emerges in each intermediate-good sector and it attempts to adopt the world technology frontier, $\bar{A}_{\mathrm{t}}$. If it succeeds, the entrepreneur will adopt the more productive 
technology $\overline{\boldsymbol{A}}_{\mathrm{t}}$ and become a monopolist because it can produce a better product than others in that sector. In that case, from equation (8), the entrepreneur enjoys the monopoly profit.

$$
\Pi_{i t}^{k}=w A_{t^{w}}
$$

On the other hand, if it fails, someone else will be chosen randomly to be a monopolist in that sector and, thus, the entrepreneur earns zero profit. By also assuming that the world technology frontier grows at an exogenous rate $\mathrm{g}$.

Implementing the new technology often requires costly research. To master and adopt the new technology, the entrepreneur must spend some resources to do research on the new technology. The more an entrepreneur spends on research, the more it's likely to succeed. Thus, assuming that the probability, $\mu$, that a technology transfer occurs successfully depends positively on the amount of the final good spent on research, $\boldsymbol{R}_{i t}$. The study also assumes that the probability of success depends negatively on the level of the world technology frontier, $\bar{A}_{\mathrm{t}}$, because when $\bar{A}_{\mathrm{t}}$ is high, the technology is more difficult to master and adopt.

Specifically, we assume that the probability of success takes the following form:

$$
\mu_{t}=\emptyset\left(\frac{B_{i t}}{A_{t}}\right)=\emptyset\left(n_{i t}\right)
$$

Where

$$
n_{i t} \equiv \frac{E_{i t}}{A_{i}}
$$

is the productivity-adjusted research expenditure. Equation (1.13) can be alternatively expressed as $n_{i t}$ as a function of $\mu_{\varepsilon}$,

$$
n_{i t}-\tilde{n}\left(\mu_{\mathfrak{v}}\right)
$$

Therefore, this study refers $\tilde{\pi}(\cdot)$ as the productivity-adjusted research cost function. Let's employ the following specific function for $\tilde{\pi}(\cdot)$ :

$$
\tilde{n}\left(\mu_{\varepsilon}\right)=\eta \mu_{\varepsilon}+\frac{\psi}{2} \mu_{\varepsilon}^{2},
$$


Where $v_{t} \psi \geqslant 0$ are research cost parameters. The key feature of this function is that the marginal cost of doing research is strictly positive even with $\xi-0$, i.e., $\tilde{t}^{t}(0)-\eta \geqslant 0$. This cost function allows two possible outcomes: If the marginal cost of research $\eta$ when $\mu-0$ is smaller than the marginal profit of adopting the world frontier technology, $u$ from equation (8), then positive research will always be done by entrepreneurs. On the other hand, if $\eta$ is greater than or equal to $z$, no research will be done. In that case, there will be no technology transfer.

Case 1: $y 5$ st The cost of research to implement the world technology frontier is sufficiently small. In this case, entrepreneurs have an incentive to do positive research. An entrepreneur's problem is to choose $\mu$ that maximizes its expected net profit,

$$
\max _{\mu} \mu_{t} \Pi_{t v}^{k}-R_{i t}=\left\{\mu_{\tau} \pi-n_{t}^{*}\left(\mu_{t}\right)\right\} \bar{A}_{t} .
$$

The first-order condition is

$$
\tilde{u}^{\prime}\left(w_{c}\right)-n-0
$$

From equation (16), by solving equation (18) for $\mu_{\tau_{t}}$ the study obtained the equilibrium probability that a technology transfer occurs,

$$
\mu^{*}=\frac{\pi-\eta_{i}}{\psi}
$$

Case 2: $\succcurlyeq \simeq \pi$ : The cost of research to implement the world technology frontier is too large. In this case, entrepreneurs have an incentive to do positive research. There is a corner solution at $\mu_{\varepsilon}-0$ and, thus, no technology transfer.

Distance to Technology Frontier

In a country with $x \leqslant x_{\text {, }}$, entrepreneurs will always do research in order to implement the world technology frontier. If the research succeeds, the entrepreneur gets to implement the current world 
technology frontier, $\bar{A}_{\mathrm{t}}$. On the other hand, if the research fails, the technology level will remain at the previous level, $A_{t-1}$. That is, each intermediate-good sector's technology level $A_{i t}$ at $\mathrm{t}$ is

$$
A_{i t}=\left\{\begin{array}{l}
A_{t} \\
A_{\varepsilon-1}
\end{array}\right\} \text { with probability }\left\{\begin{array}{c}
\mu^{*} \\
1-\mu^{*}
\end{array}\right\}
$$

Because the fraction $\mu^{*}$ of all sectors in the country move to the technology level, $\bar{A}_{t}$ and the fraction $1-\mu^{\star}$ remain at the level $A_{t-\text {. }}$, the country's average technology level, $A_{t}$, at $\mathrm{t}$ is

$$
A_{\tau}-\mu^{2} A_{\mathrm{t}}+\left(1-\mu^{5}\right) A_{\mathrm{t}-1}
$$

Then the country's proximity to the world technology frontier can be described as

$$
a_{\varepsilon}=\frac{A_{\mathrm{r}}}{\mathbb{A}_{\mathrm{t}}}
$$

By assumption, $\bar{A}_{t}$ grows at an exogenous rate g, i.e.,

$$
\frac{A_{i}}{A_{i-2}}=1+\mathrm{g}
$$

By dividing both sides of equation (21) by $\bar{A}_{\mathrm{t}}$ and inserting equations (22) and (23) in it, the study obtained the evolution of $u_{t}$,

$$
a_{t}=\mu^{*}+\frac{1-\beta}{1+g} a_{t-1}
$$

In a steady state, $u_{t-} u_{t-1}=0$ holds. Therefore, the steady-state level of the country's proximity to the world technology frontier is

$$
a^{*}=\frac{\mu^{*}(1+g)}{\mu^{4}+g}
$$

Note that the coefficient of $u_{t-1}$ in eq (24) is less than one. This guarantees that the steady-state $u^{x}$ 


\section{Macrothink}

is stable.

\section{Results and Implications}

There are three important messages from the model.

Proposition 1. In all countries with $\mathrm{m} \times \mathrm{s}$, where the cost of research to implement the world technology frontier is sufficiently small, technology transfer occurs and they will grow at the same rate as fast as the growth rate of the world technology frontier in the long run.

Proof of Proposition 1:

All countries with $m \leqslant x$ will converge to the same steady-state technology level,

$$
a^{*}=\frac{A_{c}}{A_{t}}=\frac{\mu^{*}(1+g)}{\mu^{4}+g} .
$$

As $\bar{A}_{t}$ grows at the rate g, in the steady-state and the right hand side of equation (26) is constant,

$$
\frac{d_{t}}{d_{t}}=g
$$

From equation (1.10), the country's growth rate is at the rate of technological progress. Thus the country's long-run growth rate will be the growth rate, g, of the world technology frontier,

$$
\frac{r_{s}}{r_{t}}=\frac{A_{c}}{A_{t}}=g .
$$

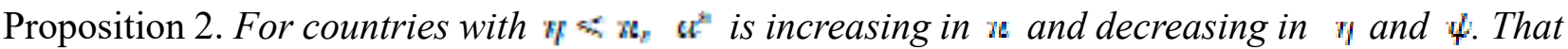
is, countries that have lower cost parameters ( $\eta$ and $\psi)$ will approach closer to the world technology frontier.

Proof of Proposition 2:

From equation (19),

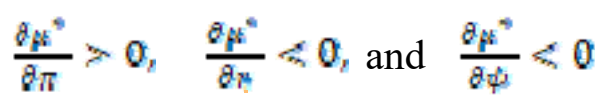

Then from equations (25) and (29), 


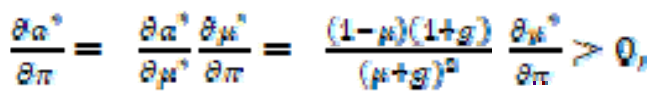

$$
\begin{aligned}
& \frac{\partial a^{*}}{\partial \eta}=\frac{\partial_{n}{ }^{n}}{\partial_{\mu}{ }^{*}} \frac{\partial_{\mu}{ }^{*}}{\partial_{\eta}}=\frac{(1-\mu)(1+g)}{(\mu+g)^{2}} \frac{\partial_{\mu}{ }^{*}}{\partial_{\eta}}<0_{n}
\end{aligned}
$$

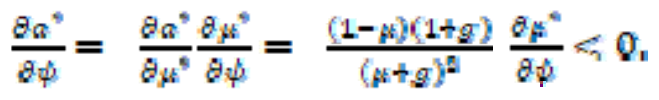

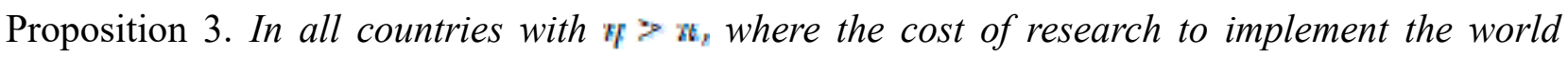
technology frontier is large, no technology transfer occurs and they will stagnate in the long run. Proof of Proposition 3:

All countries with $x \geq \pi$ will not do research and thus no technology transfer occurs. The proximity to the world technology frontier of these countries approaches zero, $u^{z}=0$, in the long run because the country's technology level remains at the same level while the world technology frontier continue to grow at the rate $\mathrm{g}$. 


\section{Macrothink}

Table 1. Econometric Results of Baseline Specification Ordinary Least Squares Results of Technology Transfer as a Panel Estimation with Additional Explanatory Variable

\begin{tabular}{|c|c|c|c|c|}
\hline Variables & Model a & Model b & Model c & Model d \\
\hline Mobile Subscription. Rate ${ }_{t}$ & $\begin{array}{l}0.005^{*} \\
(0.006)\end{array}$ & $\begin{array}{l}0.004 * \\
(0.006)\end{array}$ & $\begin{array}{l}0.001^{*} \\
(0.006)\end{array}$ & $\begin{array}{l}0.004 * \\
(0.006)\end{array}$ \\
\hline Dependence on Mobile Tech $_{\text {it }}$ & $\begin{array}{l}2.816^{* * *} \\
(1.012)\end{array}$ & $\begin{array}{l}2.820 * * * \\
(1.011)\end{array}$ & $\begin{array}{l}2.627 * * * \\
(1.010)\end{array}$ & $\begin{aligned} & 2.821 * * * \\
& (1.012)\end{aligned}$ \\
\hline${\text { Population Growth } \text { Rate }_{t}}$ & $\begin{array}{l}0.004^{*} \\
(0.568)\end{array}$ & $\begin{array}{l}0.038 * \\
(0.640)\end{array}$ & $\begin{array}{l}0.075^{*} \\
(0.562)\end{array}$ & $\begin{array}{l}0.056^{*} \\
(0.648)\end{array}$ \\
\hline Investment as share of $\mathrm{GDP}_{i t}$ & $\begin{array}{l}-0.012 * \\
(0.034)\end{array}$ & $\begin{array}{l}-0.111^{*} \\
(0.032)\end{array}$ & $\begin{array}{l}-0.009 * \\
(0.034)\end{array}$ & $\begin{array}{l}-0.009 * \\
(0.037)\end{array}$ \\
\hline -Cons & $\begin{array}{l}6.802 * * * \\
(1.897)\end{array}$ & $\begin{array}{l}6.764 * * * \\
(1.849)\end{array}$ & $\begin{array}{l}6.36 * * * \\
(0.249)\end{array}$ & $\begin{array}{l}6.486 * * * \\
(2.452)\end{array}$ \\
\hline Inflation $_{t}$ & $\begin{array}{l}-0.000^{*} \\
(0.030)\end{array}$ & - & - & - \\
\hline Tariff $_{t}$ & - & $\begin{array}{l}-0.005^{*} \\
(0.033)\end{array}$ & - & - \\
\hline Education $_{\mathrm{t}}$ & - & - & $\begin{array}{l}0.001 * * * \\
(0.000)\end{array}$ & - \\
\hline Terms of trade $t$ & - & - & - & $\begin{array}{l}0.001 * \\
(0.004)\end{array}$ \\
\hline Number of Industries & 17 & 17 & 17 & 17 \\
\hline Number of Observations & 255 & 255 & 255 & 255 \\
\hline R-Squared: & 0.1518 & 0.0519 & 0.0642 & 0.0519 \\
\hline
\end{tabular}

Dependent variable: Log of Volume of Import and the levels of significance are 1\%, $5 \%$ and 10\%.

The standard errors are robust and reported in parenthesis. The sample period is 1999-2016 (17years) 
Table 2. Econometric Results of Baseline Specification Ordinary Least Squares Results of Nigerian 37 States Economic Growth as a Panel Estimation with Additional Explanatory Variable

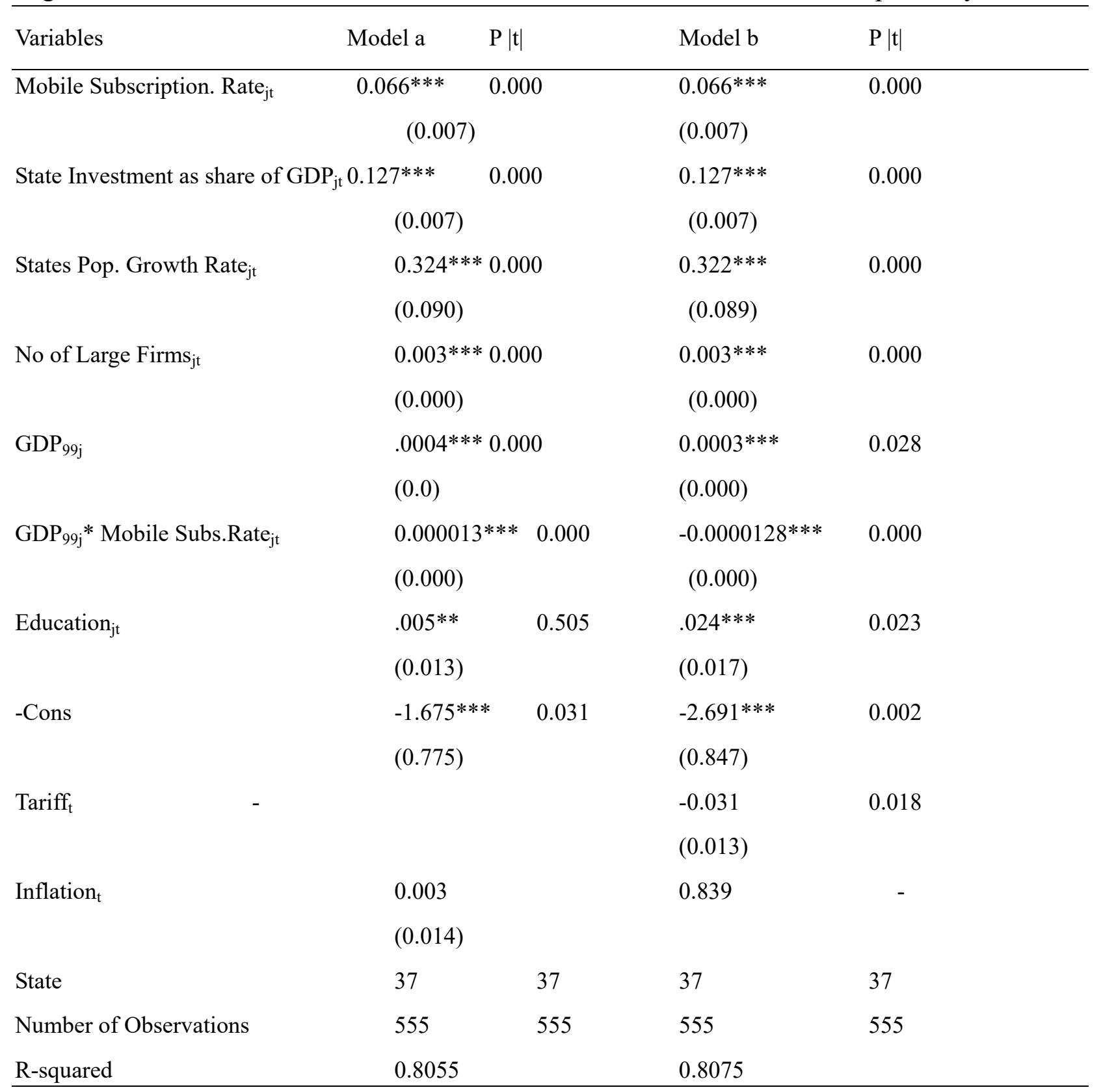

Dependent variable: Economic Growth and the levels of significance are 1\%, 5\% and 10\%

The standard errors are robust and reported in parenthesis. The sample period is 1999-2016.

\section{Conclusions}

In this research, industry and state level data are used in order to investigate the effect of wireless mobile phone technology on technology transfer and economic growth. Deregulation policy made possible greater availability of mobile phone technology that reduces the cost of technology transfer to Nigeria which eventually leads to economic growth in the period $1999-2017$. This spectacular rise in economic growth launched the country to the position of the biggest economy in Africa (Nigerian office of statistics, Abuja, 2014 and World Bank, 2014). The results of this 
study offer a robust inference that fall in the cost of transfer of technology ignites economic growth. With reference to the theoretical model and empirical evidence, the intensity of growth depends on cost of transfer of technology. This cost is reduced further by investment on education. Thereby, confirming the models claim that non - investment in things that reduce the cost of transfer of technology leads to economic stagnation. This research results further suggest that the policies that focus on transfer of technology can complement economic growth policies.

\section{Acknowledgements}

Funding Source: The Ryoichi Sasakawa Young Leaders Fellowship Fund.

Nippon Foundation Tokyo Japan sponsored and provided the funding for the study at Howard University, Washington, DC USA.

\section{References}

Aghion, P., \& Howitt, P. (1992). A model of Growth through creative Destruction. Econometrica, 60, 323-351.

Aghion, P., \& Howitt, P. (2009). The Economics of Growth. The MIT Press.

Okonjo-Iweala. (2012). Reforming the Unreformable: Lessons from Nigeria. The MIT Press.

Simon, K. (1966). Modern Economic Growth: Rate, Structure and Spread. New Haven: Yale University Press

The World Bank. (2014). Working for a world free of poverty. Retrieved from http://www.worldbank.org/

The World Bank. (2015). Working for a world free of poverty. Retrieved from http://www.worldbank.org/

\section{Copyright Disclaimer}

Copyright for this article is retained by the author(s), with first publication rights granted to the journal.

This is an open-access article distributed under the terms and conditions of the Creative Commons Attribution license (http://creativecommons.org/licenses/by/3.0/). 